\title{
Stability and Photoisomerization of Stilbenes Isolated from the Bark of Norway Spruce Roots
}

\author{
Harri Latva-Mäenpää ${ }^{1,2, * \mathbb{C}}$, Riziwanguli Wufu ${ }^{1}\left(\mathbb{D}\right.$, Daniel Mulat ${ }^{1}$, Tytti Sarjala ${ }^{3}$, Pekka Saranpää ${ }^{3, *}$ and \\ Kristiina Wähälä ${ }^{1,4, *}$
}

1 Department of Chemistry, University of Helsinki, P.O. Box 55, FI-00014 Helsinki, Finland; riziwanguli.wufu@helsinki.fi (R.W.); d.mulat@cgiar.org (D.M.)

2 Foodwest, Kärryväylä 4, FI-60100 Seinäjoki, Finland

3 Natural Resources Institute Finland, Tietotie 2, FI-02150 Espoo, Finland; tytti.sarjala@luke.fi

4 Department of Biochemistry and Developmental Biology, University of Helsinki, P.O. Box 63, FI-00014 Helsinki, Finland

* Correspondence: harri.latva-maenpaa@foodwest.fi (H.L.-M.); pekka.saranpaa@luke.fi (P.S.); kristiina.wahala@helsinki.fi (K.W.); Tel.: +358-50-4487502 (H.L.-M. \& P.S. \& K.W.)

Citation: Latva-Mäenpää, H.; Wufu, R.; Mulat, D.; Sarjala, T.; Saranpää, P.; Wähälä, K. Stability and

Photoisomerization of Stilbenes Isolated from the Bark of Norway Spruce Roots. Molecules 2021, 26, 1036. https://doi.org/10.3390/ molecules26041036

Academic Editors: Paola Di Donato and Brigida Silvestri

Received: 27 December 2020

Accepted: 5 February 2021

Published: 16 February 2021

Publisher's Note: MDPI stays neutral with regard to jurisdictional claims in published maps and institutional affiliations.

Copyright: (c) 2021 by the authors. Licensee MDPI, Basel, Switzerland. This article is an open access article distributed under the terms and conditions of the Creative Commons Attribution (CC BY) license (https:/ / creativecommons.org/licenses/by/ $4.0 /)$.

\begin{abstract}
Stilbenes or stilbenoids, major polyphenolic compounds of the bark of Norway spruce (Picea abies L. Karst), have potential future applications as drugs, preservatives and other functional ingredients due to their antioxidative, antibacterial and antifungal properties. Stilbenes are photosensitive and UV and fluorescent light induce trans to cis isomerisation via intramolecular cyclization. So far, the characterizations of possible new compounds derived from trans-stilbenes under UV light exposure have been mainly tentative based only on UV or MS spectra without utilizing more detailed structural spectroscopy techniques such as NMR. The objective of this work was to study the stability of biologically interesting and readily available stilbenes such as astringin and isorhapontin and their aglucones piceatannol and isorhapontigenin, which have not been studied previously. The effects of fluorescent and UV light and storage on the stability of trans stilbenes were assessed and the identification and characterisation of new compounds formed during our experiments were carried out by chromatographic (HPLC, GC) and spectroscopic techniques (UV, MS, NMR). The stilbenes undergo a trans to cis isomerisation under extended UV irradiation by intramolecular cyclisation (by the formation of a new C-C bond and the loss of two hydrogens) to phenanthrene structures. The characterised compounds are novel and not described previously.
\end{abstract}

Keywords: stilbenes; spruce bark; UV-light; fluorescent light; photoisomerization; trans to cis isomerization; phenanthrenes; astringin; piceid; isorhapontin; piceatannol; isorhapontigenin

\section{Introduction}

Stilbenes or stilbenoids are expected to show many future applications as drugs and functional ingredients or preservatives in food products or improving material properties. The best known stilbenoid compound is resveratrol, but there are also other interesting stilbenoids such as astringin and isorhapontin, which are derived from forest biomass and are potential starting materials for new products. The bark of Norway spruce (Picea abies L. Karst) contains the stilbenoid glucosides astringin and isorhapontin as the major polyphenolic compounds that are even found in roots [1]. Stilbenes are secondary metabolites and play an important role in the tree defence mechanism [2]. They provide protection against ultraviolet (UV) light and attacks by fungal pathogens and other microorganisms [3-5] and they also show potential to prevent pathologies associated with oxidative stress [6]. Stilbenoid glucosides are mainly localized to the inner part of the bark in the functional phloem [7] and they can be converted to their aglucones by enzymatic hydrolysis [8].

Stilbenes may exist as the trans and cis stereoisomeric forms, but naturally they overwhelmingly occur as the trans isomers due to their higher thermodynamical stability 
compared to the cis isomers [9]. However, trans-stilbenes may be isomerized to the cis form under certain conditions such as irradiation with light. Recently, Välimaa and coauthors [10] showed that UVA-induced modification of the stilbene-rich inner bark extracts increased their radical scavenging activity. The results even indicated a slightly increased antimicrobial activity after UVA-modification. The authors concluded that stilbenes from spruce bark may have potential as preservatives.

The conflicting discoveries regarding the stability of stilbenes has raised questions on the future use of stilbenes [11-13]. According to Piñeiro et al. [11], the utilization of the beneficial effects of resveratrol is limited because it is an easily oxidizable and extremely photosensitive compound. In contrast, Prokop et al. [12] showed that piceid and its aglycone resveratrol are stable polyphenols. In solution, trans-resveratrol is converted to cis-resveratrol when exposed to daylight [14]. The same photoisomerization reaction takes place when the solution is exposed to UV light [15]. According to the authors transresveratrol was fully isomerized to cis-resveratrol when exposed to UV light at $366 \mathrm{~nm}$. Montsko et al. [16] used HPLC-MS and -MS/MS together with UV spectroscopy and semiempirical quantum chemical calculations to examine the $\mathrm{UV}$ isomerization reaction of trans-resveratrol in solution under $365 \mathrm{~nm}$ UV light irradiation. Besides the formation of cisresveratrol, they claimed the formation of an oxidized derivative of trans-resveratrol with a triple bond at the centre of the molecule or the formation of a phenanthrene structure. The formation of a trihydroxy phenanthrene was supported also by Tŕíska et al. [17]. Yang et al. [18] showed that the UV irradiation of trans-resveratrol leads to the formation of a highly fluorescent compound, resveratrone, which was properly characterized by UV, MS and NMR. Computational exploration by Rodríguez et al. [19] uncovered the feasibility of singlet oxygen addition to cis or trans-resveratrol to furnish a dioxetane intermediate which spontaneously cycloreverts to benzaldehydes. Recently, Francioso et al. [20] showed that upon UV-exposure resveratrol in red wine can isomerise from the trans to the cis-isomer, which may further cyclise to 2,4,6-trihydroxy-phenanthrene. The identifications of possible new compounds derived from trans stilbenes have been mainly tentative and based only on UV or MS spectra without utilizing more detailed structural spectroscopy such as NMR.

In summary, the findings about the chemical stability of trans-resveratrol and transpiceid in solution are not fully in agreement with each other. Although the cis-isomer was formed in every case when exposed to UV or fluorescent light, the formation of additional oxidized product(s) was not observed by all investigators. A clear conclusion about the stability of trans-piceid and trans-resveratrol in solution cannot be made.

The stability studies of stilbenes have given contradictory results and been concentrated mainly on resveratrol and its glucoside piceid. Thus, the objective of this work was to study the stability of other biologically interesting and readily available stilbenes such as astringin and isorhapontin and their aglucones piceatannol and isorhapontigenin, which have not been studied in detail previously. To resolve this issue, we assessed the effects of light and storage on the stability of trans stilbenes and put more effort on the identification and characterization of new compounds formed during our experiments. The isolation and analysis of the compounds derived from the trans stilbenes studied were carried out by chromatographic (HPLC, GC) and spectroscopic techniques (UV, MS, NMR).

\section{Results and Discussion}

\subsection{The Stability of Stilbenes in Solution}

The stability of trans isomers of the isolated isorhapontin, astringin, piceid, piceatannol, resveratrol and isorhapontigenin in methanol as well as that of crude spruce bark extract dissolved in methanol was monitored for 2 weeks under two different conditions: (1) light protected: solutions of isolated stilbenes were stored in a freezer $\left(-20^{\circ} \mathrm{C}\right)$ with protection from light and (2) light unprotected: solutions of isolated stilbenes were placed in a laboratory hood and exposed to continuous fluorescent light. Similar conditions were applied to monitor the stability of stilbene constituents in crude extract prior to isolation. Trans isomers of all the isolated stilbenes were stable for the duration of the test ( 2 weeks, $366 \mathrm{~h}$ ) 
at $-20{ }^{\circ} \mathrm{C}$ if protected from light. The recovery [21] of trans isomers of five isolated stilbenes (astringin, isorhapontin, piceid, resveratrol and iso-rhapontigenin) varied in the range of $97-101 \%$ and that of trans-piceatannol $73-106 \%$. These compounds as well as the crude extract were stable for at least two weeks in darkness at $-20^{\circ} \mathrm{C}$. Isolated stilbenes were unstable when exposed to fluorescent light. HPLC-UV analysis of trans-resveratrol revealed that irradiation with fluorescent light reduced the trans-resveratrol peak and a new one appeared with a longer retention time [21].

HPLC-DAD, HPLC-DAD/MS and HPLC-DAD/MS/MS analyses were used for the tentative identification of the new peaks from photoisomerized isorhapontin, astringin, piceid, piceatannol, resveratrol and isorhapontigenin. UV absorption maxima of the new products at $\sim 220$ and $\sim 280 \mathrm{~nm}$ are characteristic for the cis-stilbene chromophore [22]. The determined $\mathrm{m} / \mathrm{z}$ of $[\mathrm{M}-\mathrm{H}]^{-}$ion indicated molecular weights similar to the starting material. NMR analysis confirmed that trans-stilbenes (isorhapontin, isorhapontigenin, piceid and resveratrol) gave new products as cis isomers (Table 1). Light exposure has been shown to cause the isomerization of trans-piceid and trans-resveratrol to cis-piceid and cis-resveratrol respectively $[15,23]$ which is in line with our observations.

Table 1. HPLC-DAD-MS characteristics $\left(\mathrm{t}_{R}(\mathrm{~min}), \mathrm{UV}\right.$ profile and $\left.[\mathrm{M}-\mathrm{H}]^{-}, m / z\right)$ of the new products after light exposure of stilbene solutions.

\begin{tabular}{|c|c|c|c|c|}
\hline Sample Name & Products & $\mathbf{t}_{R}(\min )$ & UV Profile & {$[\mathrm{M}-\mathrm{H}]^{-}, m / z$} \\
\hline \multirow{2}{*}{ trans-astringin } & trans-astringin & 11.8 & trans-stilbene & 405 \\
\hline & new peak & 16 & $\lambda_{\max } \sim 260$ & 403 \\
\hline \multirow{2}{*}{ trans-piceid } & trans-piceid & 16.3 & trans-stilbene & 389 \\
\hline & new peak & 27.5 & cis-stilbene & 389 \\
\hline \multirow{2}{*}{ trans-isorhapontin } & trans-isorhapontin & 17.5 & trans-stilbene & 419 \\
\hline & new peak & 28.3 & cis-stilbene & 419 \\
\hline trans-piceatannol & trans-piceatannol & 18.6 & trans-stilbene & 243 \\
\hline \multirow[b]{2}{*}{ trans-resveratrol } & $\begin{array}{l}\text { no peak detected } \\
\text { trans-resveratrol }\end{array}$ & 25 & trans-stilbene & 227 \\
\hline & new peak & 32.3 & cis-stilbene & 227 \\
\hline \multirow{2}{*}{ trans-isorhapontigenin } & trans-isorhapontigenin & 26.4 & trans-stilbene & 257 \\
\hline & new peak & 33.1 & cis-stilbene & 257 \\
\hline
\end{tabular}

trans-Astringin exposed to fluorescent light suffers a loss of two hydrogen atoms from the trans-astringin molecule yielding a new product (Table 1) with maximum absorption at $\sim 260 \mathrm{~nm}$ and molecular mass $404 \mathrm{Da}$ as can be deduced from $[\mathrm{M}-\mathrm{H}]^{-}=403 \mathrm{~m} / \mathrm{z}$.

Trans-piceid, trans-resveratrol and trans-astringin showed the highest instability under fluorescent light exposure whereas trans-isorhapontigenin and trans-isorhapontin were more stable (Figure 1). The steric hindrance due to the methoxy substituent in the structure of isorhapontin and its aglucone discourages the trans to cis isomerization.

The effect of fluorescent light on the stability of isolated stilbenes can also be seen from the yield of new products (Figure 2). Maximum conversion resulted from the isomerization of the trans forms of resveratrol and piceid to their corresponding cis isomers after 2 week fluorescent light exposure at room temperature. As shown in Figure 2, the conversion rate is faster for the initial $36 \mathrm{~h}$ and becomes slower thereafter.

Crude spruce bark extract solutions were not significantly destablized by exposure to fluorescent light. It is known that in addition to stilbenes, spruce bark contains phenolic compounds such as lignans, flavonoids and tannins $[1,7,10]$ which may influence the action of light on the stilbenes. 


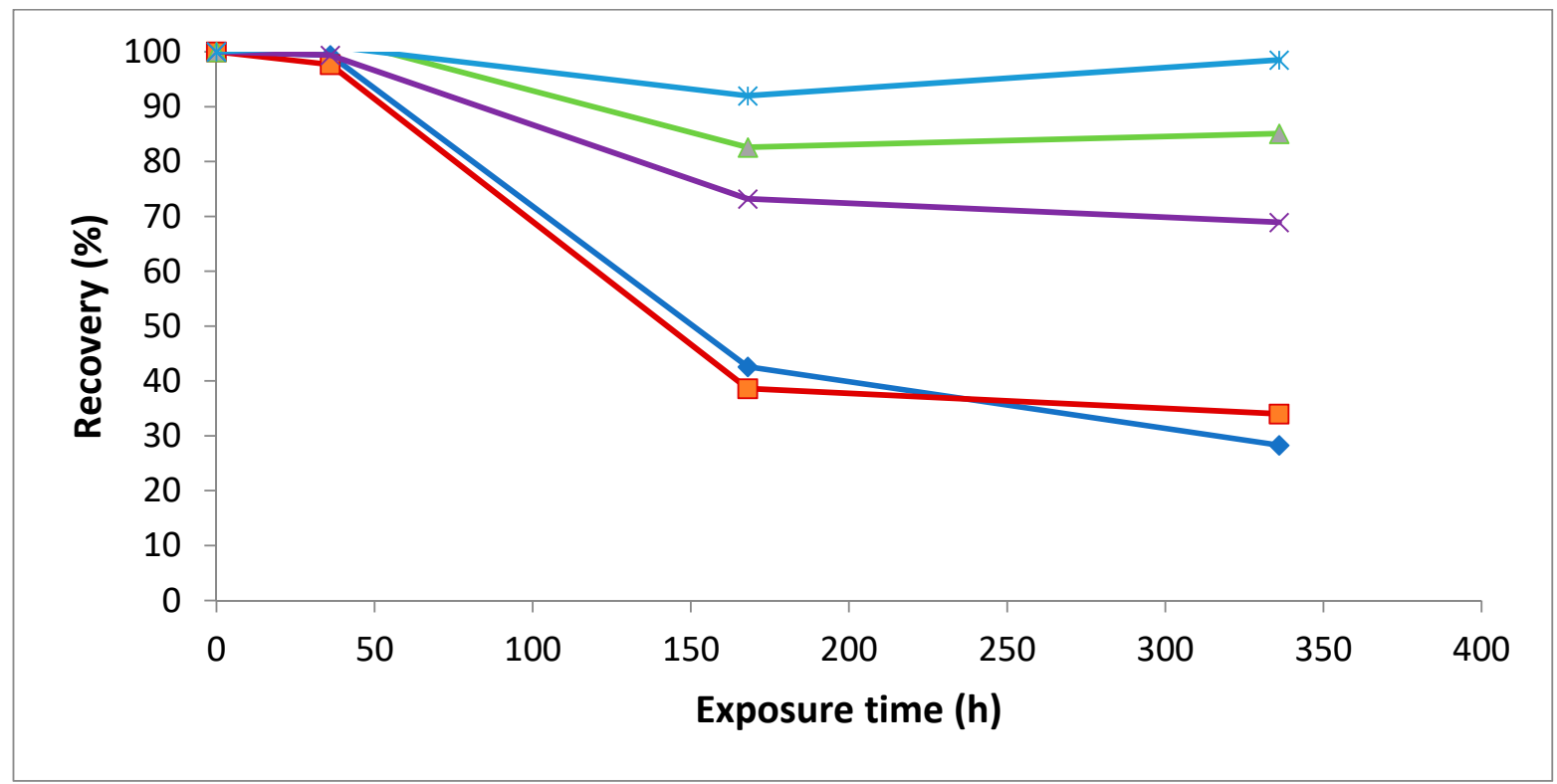

Figure 1. Effect of fluorescent light exposure on the stability of trans-stilbenes isolated in $\mathrm{MeOH}$ solution. - transastringin, - trans-piceid, - trans-isorhapontin, $\leftarrow$ trans-resveratrol and $*$ trans-isorhapontigenin.

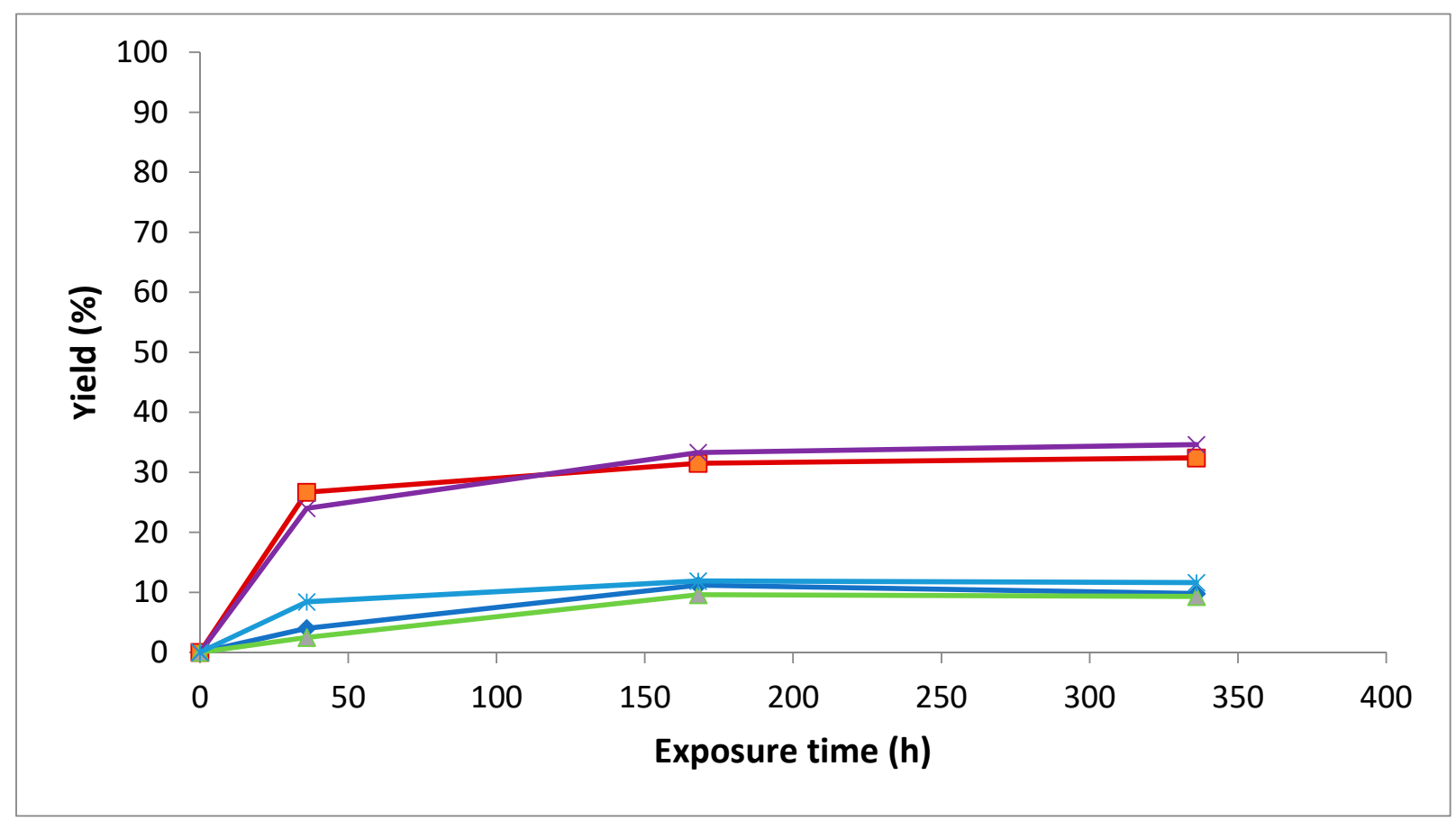

Figure 2. The yield of cis stilbenes and a new compound (derived from trans-astringin) formed by the exposure of corresponding trans stilbenes to fluorescent light in $\mathrm{MeOH}$ solution. - peak derived from cis-astringin, - cis-piceid, $\rightarrow$ cis-isorhapontin, $\leftarrow$ cis-resveratrol and $*$ cis-isorhapontigenin.

\subsection{Stability Assessment of Stilbenes in Solid Crude Extract}

Stilbene glucosides (trans-astringin, trans-isorhapontin and trans-piceid) in the solid crude extract showed $100 \%$ recovery when assessed for their stability under three different conditions: (1) Light protected: solid extract in a capped glass vial stored in freezer $\left(-20^{\circ} \mathrm{C}\right)$ with protection from light; (2) Light unprotected capped glass vial: solid extract in a capped glass vial exposed to continuous fluorescent light and (3) Light unprotected uncapped glass vial: solid extract in glass vial left uncapped and placed on laboratory cabinet to expose it to 
continuous fluorescent light [21]. Even if in contact with air in uncapped vials, the oxidation or isomerization of the evaluated stilbenes were not observed. In other studies, solid resveratrol and piceid in glass vials protected from light were stable [12], and furthermore the solid trans-resveratrol and trans-piceid are not very sensitive to UV/fluorescent light, elevated temperature or humidity or atmospheric oxidants at ambient conditions [21,23].

\subsection{UV Stability of Stilbenes}

The isomerization of crude trans stilbenes extract, hydrolysed (containing stilbene aglucones) and non-hydrolysed (containing stilbene glucosides), to thessss cis forms started immediately after exposure to UV light $(366 \mathrm{~nm})$ and most of the trans structures had disappeared after 10-30 min (Figure 3). trans-Astringin and trans-isorhapontin showed the lowest rate of disappearance of the trans form.

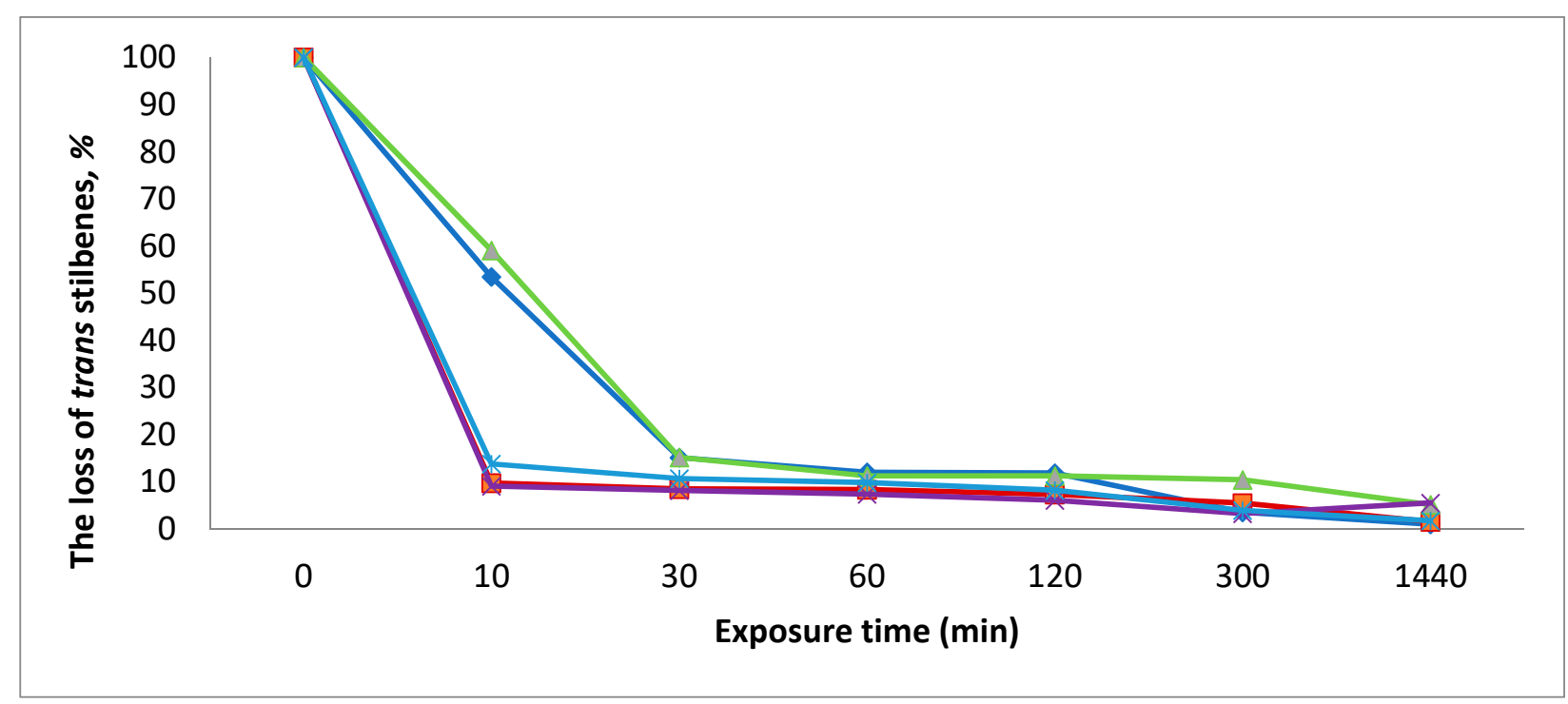

Figure 3. Effect of UV light exposure on the stability of isolated trans-stilbenes in MeOH solution. - trans-astringin, - trans-piceid, $\rightarrow$ trans-isorhapontin, $\leftarrow$ trans-resveratrol and $*$ trans-isorhapontigenin.

The exposure of the isolated stilbenes in methanol solution, hydrolysed (containing stilbene aglucones) and non-hydrolysed (containing stilbene glucosides), crude extract under UV irradiation lamp ( $366 \mathrm{~nm}$ ) caused the isomerization of trans stilbenes to cis forms. After 10-30 min of UV exposure most of the trans structures were absent (Figure 3). The proportion of cis stilbenes increased 10-60 min after starting the exposure (Figure 4). After that the proportion of cis structures decreased due to transformation of cis stilbenes to other products.

The GC-MS information of the trans stilbenes isolated and the compounds derived from those during UV irradiation $(366 \mathrm{~nm}$ ) is presented in Table 2. In general, trans-to-cisisomerisation took place rapidly and after that all the compounds lost two hydrogens from their structures presumably by oxidation. In the case of piceatannol, the cis form was not detected by GC-MS. 


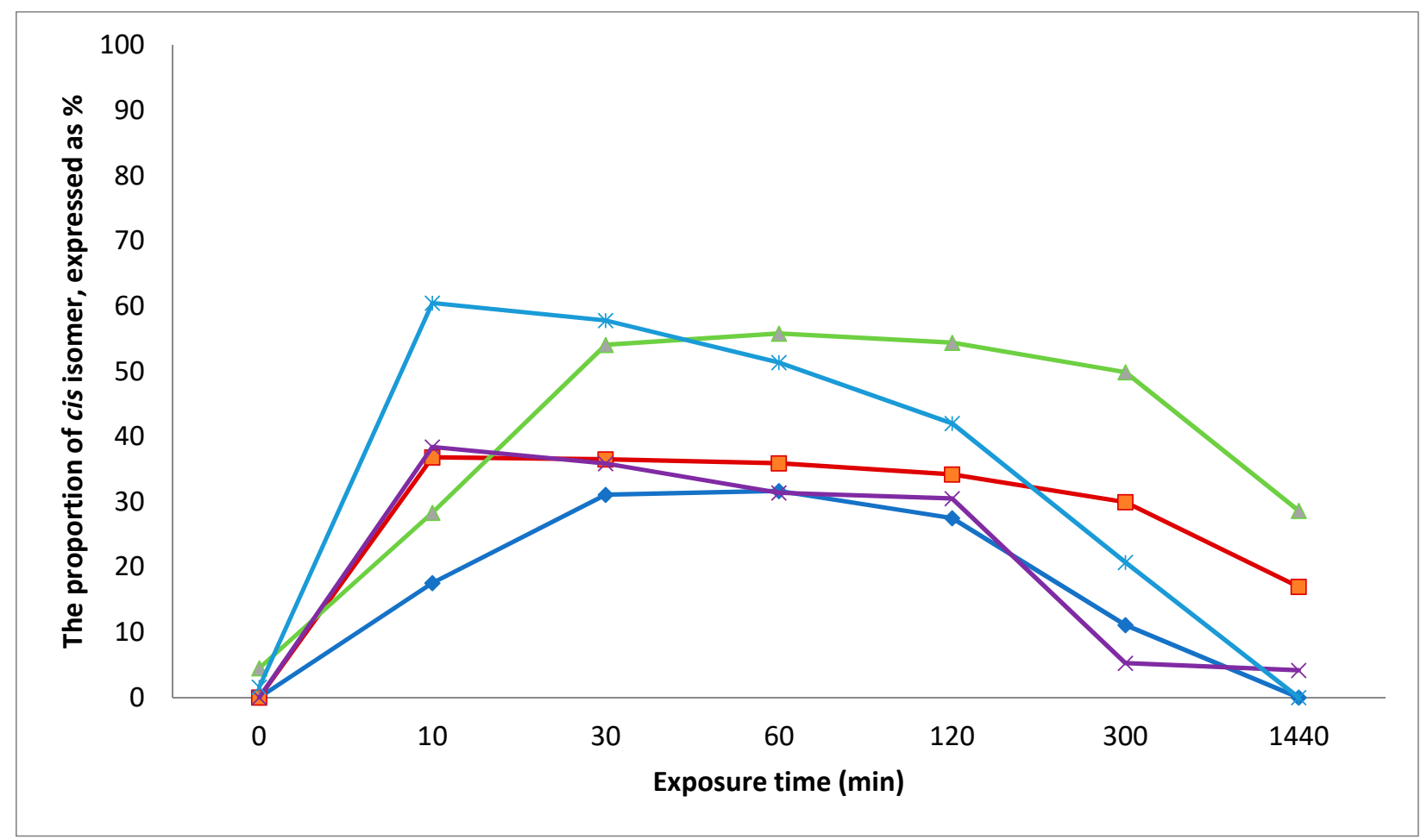

Figure 4. The proportion of cis stilbenes due to the exposure of trans isomers to UV light in MeOH solution. cis-astringin, $\rightarrow$ cis-piceid, $\rightarrow$ cis-isorhapontin, $\leftarrow$ cis-resveratrol and $\because$ cis-isorhapontigenin.

Table 2. GC-MS ${ }^{1}$ characteristics of the stilbenes and new products obtained from the UV light ( $366 \mathrm{~nm}$ ) exposure experiment.

\begin{tabular}{|c|c|c|c|c|c|}
\hline Sample & Products & $\begin{array}{c}\text { Major Compound } \\
\text { After UV } \\
\text { Irradiation } \\
(0 \mathrm{~h}, 2 \mathrm{~h}, 24 \mathrm{~h})\end{array}$ & $\begin{array}{l}\text { GC-MS Retention } \\
\text { Time (min) }\end{array}$ & $\begin{array}{c}\text { GC-MS } \\
\text { (TMSI), } m / z\end{array}$ & $\begin{array}{c}\text { HPLC } \\
\text { UV Profile }\end{array}$ \\
\hline \multirow{3}{*}{ trans-astringin } & trans-astringin & $0 \mathrm{~h}$ & 41.72 & 532 & trans-stilbene \\
\hline & cis-astringin & $2 \mathrm{~h}$ & 32.04 & 532 & cis-stilbene \\
\hline & new peak & $24 \mathrm{~h}$ & 34.48 & 530 & $\lambda_{\max } \sim 260$ \\
\hline \multirow{3}{*}{ trans-piceid } & trans-piceid & $0 \mathrm{~h}$ & 38.42 & 444 & trans-stilbene \\
\hline & cis-piceid & $2 \mathrm{~h}$ & 30.30 & 444 & cis-stilbene \\
\hline & new peak & $24 \mathrm{~h}$ & 31.77 & 442 & $\lambda_{\max } \sim 260$ \\
\hline \multirow{5}{*}{ trans-isorhapontin } & trans-isorhapontin & $0 \mathrm{~h}$ & 42.45 & 474 & trans-stilbene \\
\hline & cis-isorhapontin & $2 \mathrm{~h} / 24 \mathrm{~h}$ & 31.62 & 474 & cis-stilbene \\
\hline & new peak 1 & $24 \mathrm{~h}$ & 30.43 & 472 & $\lambda_{\max } \sim 260$ \\
\hline & new peak 2 & $24 \mathrm{~h}$ & 34.48 & 472 & $\lambda_{\max } \sim 260$ \\
\hline & new peak 3 & $24 \mathrm{~h}$ & 43.54 & 472 & $\lambda_{\max } \sim 260$ \\
\hline \multirow{3}{*}{ trans-piceatannol } & trans-piceatannol & $0 \mathrm{~h}$ & 22.76 & 532 & trans-stilbene \\
\hline & new peak 1 & $2 \mathrm{~h}$ & 21.57 & 530 & $\lambda_{\max } \sim 260$ \\
\hline & new peak 1 & $24 \mathrm{~h}$ & 21.57 & 530 & $\lambda_{\max } \sim 260$ \\
\hline \multirow{3}{*}{ trans-resveratrol } & trans-resveratrol & $0 \mathrm{~h}$ & 20.00 & 444 & trans-stilbene \\
\hline & cis-resveratrol & $2 \mathrm{~h}$ & 13.89 & 444 & cis-stilbene \\
\hline & new peak & $24 \mathrm{~h}$ & 18.64 & 442 & $\lambda_{\max } \sim 260$ \\
\hline \multirow{3}{*}{$\begin{array}{c}\text { trans- } \\
\text { isorhapontigenin }\end{array}$} & $\begin{array}{l}\text { trans- } \\
\text { isorhapontigenin }\end{array}$ & $0 \mathrm{~h}$ & 22.55 & 474 & trans-stilbene \\
\hline & cis-isorhapontigenin & $2 \mathrm{~h}$ & 15.62 & 474 & cis-stilbene \\
\hline & new peak & $24 \mathrm{~h}$ & 16.36 & 472 & $\lambda_{\max } \sim 260$ \\
\hline
\end{tabular}

In the hydrolysed crude extract, all three trans stilbene aglucones isomerized to the cis forms, which were the major compounds at $2 \mathrm{~h}$. The new peaks with loss of two hydrogens derived from stilbene aglucones were found from the hydrolysed crude extract after $24 \mathrm{~h}$ 
UV irradiation by GC-MS as in the case of isolated stilbene aglucones. The same was true for the non-hydrolysed extracts containing the trans stilbene glucosides.

\subsection{Isolation and Identification of the New Compounds Formed during UV Irradiation}

The new compounds derived from the trans stilbenes during UV light exposure were fractionated by using preparative HPLC and identified by NMR and MS. The stilbenes showed isomerization from trans to cis form during UV light irradiation followed by the loss of two hydrogens $(-2 \mathrm{H})$ after a longer time of irradiation. ESI-TOF-MS was used to identify the fractions derived from stilbene glucosides, astringin (Figure 5) and isorhapontin (Figure 6) (Table 3) and EI-MS to identify the fractions derived from hydrolyzed stilbenes piceatannol and isorhapontigenin.

Datafile Name:F1astringinUV100ul001.Icd

Sample Name:F1astringinUV100ul

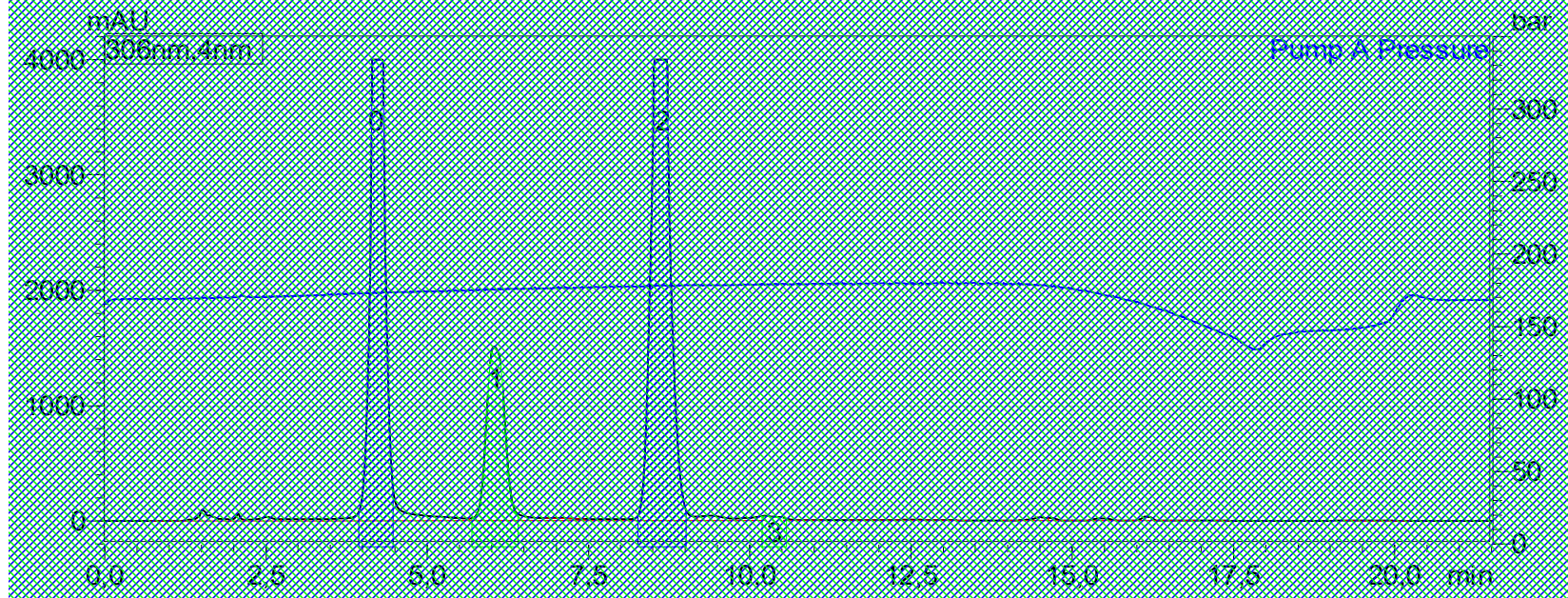

Figure 5. Sample chromatogram of preparative HPLC fractionation of stilbenes derived from UV-exposed astringin.

Datafile Name:F3isorhapontinUV100ul001.Icd Sample Name:F3isorhapontinUV

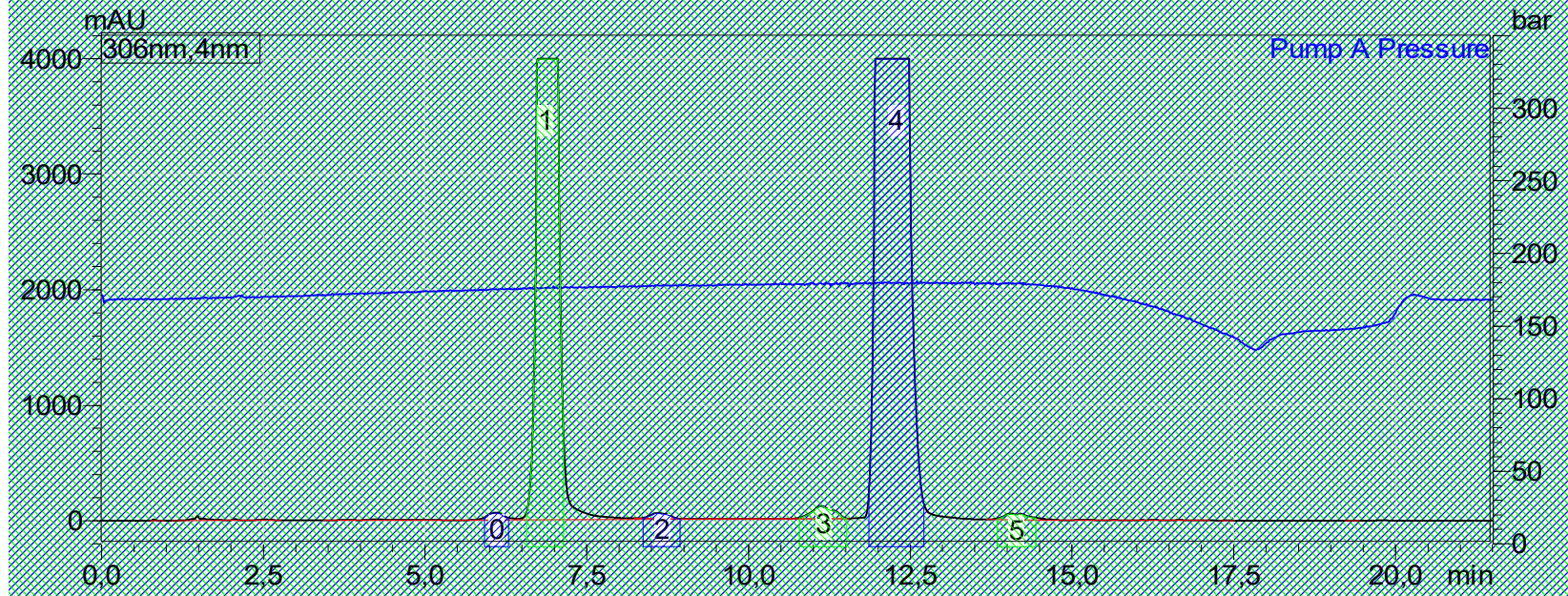

Figure 6. Sample chromatogram of preparative HPLC fractionation of stilbenes derived from UV-exposed isorhapontin. 
Table 3. Identification of compounds derived from trans-astringin (F1) and trans-isorhapontin (F3) by HR ESI-TOF-MS.

\begin{tabular}{ccccc}
\hline Compound & Stilbene & {$[\mathbf{M}-](\mathbf{m} / \mathbf{z})$} & Calcd. & Formula \\
\hline F1.1 & trans-astringin & 405.1180 & 405.1186 & $\mathrm{C}_{20} \mathrm{H}_{21} \mathrm{O}_{9}$ \\
F1.2 & new peak & 403.1036 & 403.1029 & $\mathrm{C}_{20} \mathrm{H}_{19} \mathrm{O}_{9}$ \\
F1.3 & cis-astringin & 405.1243 & 405.1186 & $\mathrm{C}_{20} \mathrm{H}_{21} \mathrm{O}_{9}$ \\
F3.1 & trans-isorhapontin & 419.1479 & 419.1342 & $\mathrm{C}_{21} \mathrm{H}_{23} \mathrm{O}_{9}$ \\
F3.2 & new peak & 417.1321 & 417.1186 & $\mathrm{C}_{21} \mathrm{H}_{21} \mathrm{O}_{9}$ \\
F3.3 & new peak & 417.1327 & 417.1186 & $\mathrm{C}_{21} \mathrm{H}_{21} \mathrm{O}_{9}$ \\
F3.4 & cis-isorhapontin & 419.1487 & 419.1342 & $\mathrm{C}_{21} \mathrm{H}_{23} \mathrm{O}_{9}$ \\
F3.5 & new peak & 417.1321 & 417.1186 & $\mathrm{C}_{21} \mathrm{H}_{21} \mathrm{O}_{9}$ \\
\hline
\end{tabular}

2.5. The Structural Elucidation of New Peaks Formed from Astringin (and Its Aglycone Piceatannol) and Isorhapontin (and Its Aglycone Isorhapontigenin)

For the new compound derived from trans-astringin (F1.2), the ESI-MS spectrum showed $403.1036 \mathrm{~m} / \mathrm{z}$ as the parent peak. Its molecular mass is two units less than that of trans- and cis-astringin. In the ${ }^{1} \mathrm{H}-\mathrm{NMR}$ spectrum, there are six proton signals between 6.0-10.0 ppm. Alkene $\mathrm{H}$ signals with a larger coupling constant (ca $12-16 \mathrm{~Hz}$ ) were absent from the aromatic range. The signal $\delta 9.008(1 \mathrm{H}, \mathrm{s})$ could be an aldehyde proton, but the aldehyde carbon signal (around $200 \mathrm{ppm}$ ) however does not appear in the ${ }^{13} \mathrm{C}$ NMR spectrum. This proton bound to carbon (about $104 \mathrm{ppm}$ ) is therefore an aromatic proton. The signals $7.435(1 \mathrm{H}, \mathrm{d}, J=9 \mathrm{~Hz})$ and $7.319(1 \mathrm{H}, \mathrm{d}, J=9 \mathrm{~Hz})$ belong to a pair of ortho-coupled aromatic protons. They do not couple with other aromatic protons. The signals $6.968(1 \mathrm{H}, \mathrm{d}, J=2.4 \mathrm{~Hz})$ and $6.843(1 \mathrm{H}, \mathrm{d}, J=2.7 \mathrm{~Hz})$ had almost the same coupling constants, so they may be from the same aromatic ring. 2D NMR (COSY, HSQC, and $\mathrm{HMBC}$ ) also supported these findings. Based on the above evidence the new structure was identified (F1.2) as 7-O- $\beta$-D-glucosyl-2,3,5-trihydroxyphenanthrene (Figure 7).<smiles>Oc1cc2ccc3cc(OC4CCCCC4)cc(O)c3c2cc1O</smiles>

Figure 7. The proposed structure of F1.2, a phenanthrene molecule derived from the stilbene astringin by a photochemical cyclization and dehydrogenation induced by UV irradiation.

For the new compounds derived from trans-isorhapontin, the negative ESI-MS spectrum showed the strongest peak at $417.1321 \mathrm{~m} / \mathrm{z}$ (for F3.2, F3.3, F3.5) two units less than trans- and cis-isorhapontin. ${ }^{1} \mathrm{H}-\mathrm{NMR}$ and $2 \mathrm{D}$ NMR signals of F3.2 were almost the same as those in fraction F1.2, except for the $\mathrm{OCH}_{3}$ signal at 3.992. F3.5 showed the shift of the methoxy signal to $3.432 \mathrm{ppm}$, which may be due to the formation of different isomers of phenanthrenes since the positions of hydroxy and methoxy groups adjacent to each other have two alternative arrangements in the cis isomer from which is the starting point of phenanthrene formation. F3.3 was the mixture of the fractions F3.2 and F3.5. The new structures identified (F3.2 and F3.5) are 7-O- $\beta$-D-glucosyl-3,5-dihydroxy2-methoxyphenanthrene and 7-O- $\beta$-D-glucosyl-2,5-dihydroxy-3-methoxyphenanthrene (Figure 8). 
<smiles>COc1cc2ccc3cc(OC4CCCCC4)cc(O)c3c2cc1O</smiles><smiles>COc1cc2c(ccc3cc(OC4CCCCC4)cc(O)c32)cc1O</smiles>

Figure 8. The proposed structures of F3.2 and F3.5, phenanthrene molecules derived from the stilbene isorhapontin due to a photochemical cyclization and dehydrogenation induced by UV irradiation.

The novel compounds derived from trans-piceatannol and trans-isorhapontigenin show similar phenanthrene NMR signals. Our NMR data in combination with our UV and MS data suggest that the photochemical transformation of stilbenes to phenanthrene structures goes by way of an intramolecular cyclisation forming a new C-C bond. The phenanthrene structures observed in our studies are supported by earlier data based on the studies of trans-resveratrol and its glucoside, piceid $[16-18,24]$ and by the studies of pure stilbene molecule itself $[25,26]$. Our study of various stilbenes isolated from bark extracts now establishes their general behavior exhibited in the photochemical transformation to phenanthrene structures. The suggested electrocyclic mechanism of photochemical transformation of cis-stilbenes to phenanthrenes is shown in Figure 9.<smiles>CC(C)(C)c1cccc(/C=C/c2ccccc2)c1</smiles>

M<smiles>C(=Cc1ccccc1)c1ccccc1</smiles>

M<smiles>CCCC1[CH]C23C=CC=CC2C=CC=C3C=CC=C1</smiles><smiles>N#[W]</smiles>

Figure 9. Proposed mechanism of photochemical transformation of cis stilbenes to phenanthrenes.

Photochemical transformations of trans-astringin and trans-isorhapontin (and of their aglycones, trans-piceatannol and trans-isorhapontigenin) derived from Norway spruce root bark have been reported and described (Figure 10). These molecules formed by photochemical transformation of naturally occurring stilbenes have not been reported earlier in the literature.

The UVA-induced modification of the stilbene-rich inner bark extracts increased the radical scavenging activity [20]. The results also indicate even a slightly increased antimicrobial activity after UVA-modifications [20]. Thus stilbenes have commercial potential as e.g., preservatives. 


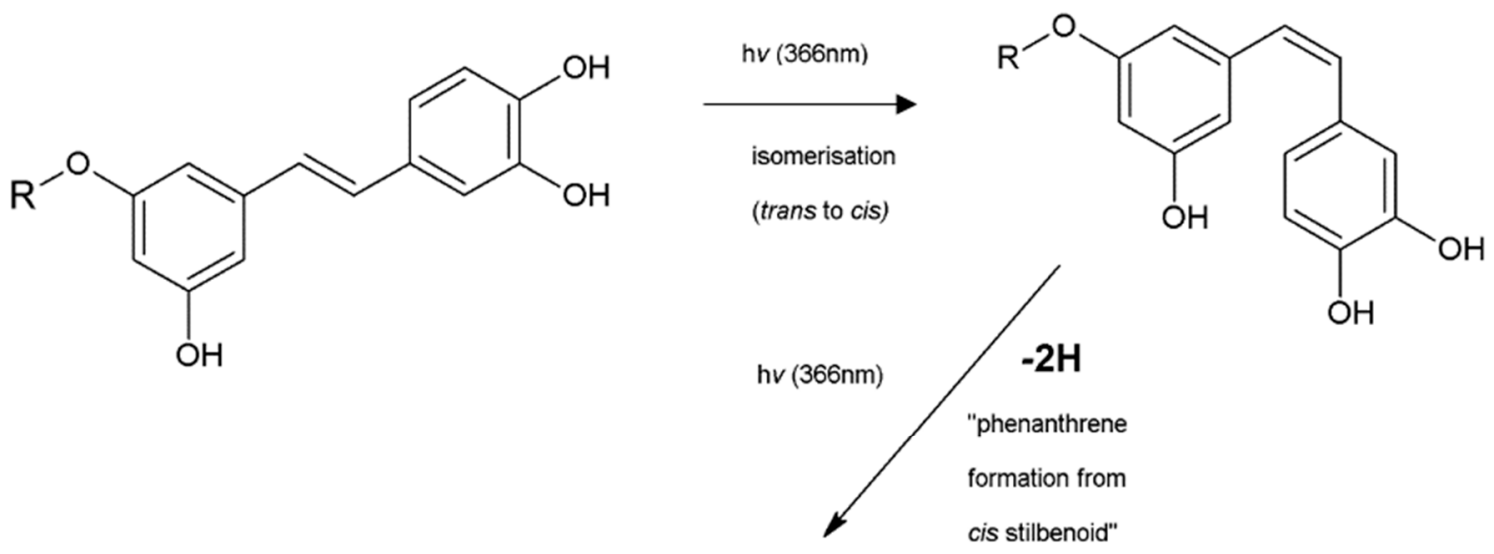<smiles>[R]Oc1cc(O)c2c(ccc3cc(O)c(O)cc32)c1</smiles><smiles>[R]Oc1cc(O)cc(/C=C/c2ccc(O)c(OC)c2)c1</smiles>

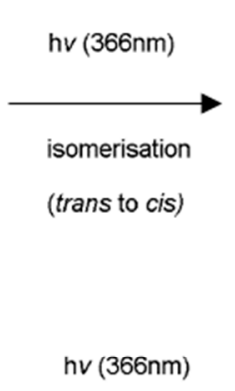<smiles>[R]Oc1cc(O)cc(/C=C\c2ccc(O)c(OC)c2)c1</smiles>

\section{$-2 \mathrm{H}$}

"phenanthrene

formation from

cis stilbenoid"<smiles>[R]Oc1cc(O)c2c(ccc3cc(OC)c(O)cc32)c1</smiles><smiles>[R]CC(=O)Oc1cc(O)c2c(ccc3cc(O)c(OC)cc32)c1</smiles><smiles>[O-][C@H]1O[C@H](CO)C(O)[C@H](O)C1O</smiles>

Figure 10. Proposed photochemical transformation of selected trans stilbenes (astringin and isorhapontin and their aglycones piceatannol and isorhapontigenin) derived from Norway spruce root bark. $\mathrm{R}=-\mathrm{H}$ or $-\mathrm{O}-\beta$-D-glucoside $(\mathrm{Glu}) .-2 \mathrm{H}=\mathrm{loss}$ of two hydrogens 


\section{Materials and Methods}

\subsection{Bark Material}

Thick roots of Norway spruce (Picea abies [L.] Karst) were collected from trees growing on mineral soil from Parkano (Lapinneva, Western Finland) in June 2010. The detailed sample information is given in Latva-Mäenpää et al. [1]. The samples were collected from the underground parts of the roots close to the stem. After debarking the bark material of the roots was immediately frozen at $-20^{\circ} \mathrm{C}$. It was splintered, freeze-dried for $2-3$ days, subsequently ground and stored in a freezer $\left(-20^{\circ} \mathrm{C}\right)$ prior to analysis.

\subsection{Extraction of Bark Material}

The bark extract of Norway spruce was obtained by sequential extraction of the powdered bark ( $2 \mathrm{~g})$ first with hexane to remove the hydrophobic constituents, followed by $95 \% \mathrm{~V} / \mathrm{V}$ ethanol to collect the hydrophilic stilbene constituents using an Accelerated Solvent Extraction (ASE 350, Dionex, Sunnyvale, CA, USA). The ASE sequential extraction method $[1,7,21]$ was: (1) $n$-hexane extraction: temperature, $90^{\circ} \mathrm{C}$; static time, $5 \mathrm{~min}$; two cycles and (2) ethanol:water (95:5 V/V) extraction: temperature, $100^{\circ} \mathrm{C}$; static time, $5 \mathrm{~min}$; two cycles for $2 \mathrm{~g}$ sample or three cycles for $3 \mathrm{~g}$ of sample. The crude extract was diluted 1:10 with $\mathrm{MeOH}$ before injecting $5 \mu \mathrm{L}$ into the HPLC-DAD, HPLC-DAD/ESI-MS and HPLC-DAD/ESI-MS/MS instruments.

The stilbene content of the non-hydrolysed samples was enriched in an XAD-7HP polymer resin filled column, which was previously conditioned with water. Polyphenolic compounds were absorbed in a resin material and water-soluble compounds such as sugars were washed away with water. Stilbene glucosides were collected from ethanol-water eluates. All samples were stored at $-20{ }^{\circ} \mathrm{C}$ with light protection until further processing. For producing and isolating hydrolysed stilbene aglucones the other $95 \% \mathrm{~V} / \mathrm{V}$ ethanol extract was evaporated to dryness by rotary evaporation at $40{ }^{\circ} \mathrm{C}$ and dissolved in $15 \mathrm{~mL}$ of sodium acetate buffer $(0.1 \mathrm{M}, \mathrm{pH}$ ) solution. $15 \mathrm{~mL}$ of $\beta$-glucosidase enzyme $(3 \mathrm{mg} / \mathrm{mL})$ was suspended in the above solution and incubated in a laboratory oven at $39{ }^{\circ} \mathrm{C}$ for 3 days. The hydrolysed samples were enriched in a polymer resin as mentioned above and collected from ethyl acetate eluates. The stilbene glucoside and the stilbene aglucone fract e ions were evaporated to dryness by rotary evaporation at $40{ }^{\circ} \mathrm{C}$ and used for preparativHPLC, HPLC, HPLC-DAD/MS and HPLC-NMR analyses.

\subsection{HPLC-DAD Analyses}

Separation of stilbenes from the extract of the root bark of Norway spruce was carried out by HPLC. A Model 1100 series liquid chromatography system (Hewlett-Packard, Santa Clara, CA, USA) with a quaternary pump, degasser, autosampler, column oven and an Agilent 1100 series diode array detector coupled to a Hewlett-Packard Chem Station was used for analysis. HPLC separation was performed on an Xbridge-C18 column $\left(4.8 \times 150 \mathrm{~mm}, 5 \mu \mathrm{m}\right.$, Waters, Milford, MA, USA) using a mobile phase of $\mathrm{H}_{2} \mathrm{O}$ and $\mathrm{MeOH}$ with a flow rate of $0.8 \mathrm{~mL} / \mathrm{min}$. The mobile phase gradient program was $90: 10(\mathrm{t}) 0 \mathrm{~min}$, 75:25 (t) $3 \mathrm{~min}, 60: 40$ (t) $21 \mathrm{~min}$, 50:50 (t) $30 \mathrm{~min}, 30: 70$ (t) $33 \mathrm{~min}$, 10:90(t) 35-36 min and 90:10 (t) 37-39 min. The UV profiles of eluates were monitored with DAD in the range of 200-400 nm. Detection was carried out at $286 \mathrm{~nm}$ and $306 \mathrm{~nm}$ for cis and trans stilbenes, respectively ( $260 \mathrm{~nm}$ was also used for detection in UV experiments). Measurements were carried out in duplicate or in triplicate. The mobile phase $\left(\mathrm{H}_{2} \mathrm{O}\right.$ and $\left.\mathrm{MeOH}\right)$ gradient program was further modified for the structural characterisation of the compounds formed after UV irradiation and this separation was performed by Prominence HPLC instrument (Shimadzu, Canby, OR, USA); the modified mobile phase gradient program was 72:28 (t) $0 \mathrm{~min}, 60: 40$ (t) $9 \mathrm{~min}, 50: 50$ (t) $13.5 \mathrm{~min}, 30: 70$ (t) $15 \mathrm{~min}, 10: 90(\mathrm{t}) 17.5 \mathrm{~min}$ and 72:28 (t) $18-21.5 \mathrm{~min}$ with a flow rate of $1.4 \mathrm{~mL} / \mathrm{min}$. 


\subsection{Isolation of Stilbenes by Preparative HPLC}

Preparative isolation was performed using a Waters $600 \mathrm{HPLC}$ instrument on a Waters Xbridge-C18 column $(19 \times 150 \mathrm{~mm}, 5 \mu \mathrm{m})$ using a mobile phase of water and acetonitrile with a flow rate of $7 \mathrm{~mL} / \mathrm{min}$. The mobile phase gradient programs for the non-hydrolysed and hydrolyseSunnd samples were 90:10 (t) $0 \mathrm{~min}$, 85:15 (t) $5 \mathrm{~min}, 70: 30(\mathrm{t}) 25 \mathrm{~min}, 50: 50(\mathrm{t})$ $30 \mathrm{~min}, 10: 90$ (t) $35 \mathrm{~min}, 90: 10$ (t) 37-40 $\mathrm{min}$ and 90:10 (t) $0 \mathrm{~min}, 85: 15$ (t) $10 \mathrm{~min}, 70: 30$ (t) $35 \mathrm{~min}, 50: 50$ (t) $38 \mathrm{~min}, 10: 90$ (t) $40 \mathrm{~min}, 90: 10$ (t) $43-45 \mathrm{~min}$, respectively. The fractions of the hydrolysed extract and the non-hydrolysed extract were collected at 7.5, 11.2, $12.2 \mathrm{~min}$ and 13.3, 18.3, $19.5 \mathrm{~min}$. All collected fractions ( $7 \mathrm{~mL}$ each) were evaporated to dryness by a Biotage SB4 evaporator (Uppsala, Sweden) and dissolved in $10 \mathrm{~mL}$ of $\mathrm{MeOH}$. The dissolved stilbenes were filtered through a $0.45 \mu \mathrm{m}$ microporous membrane and stored in freezer at $-20{ }^{\circ} \mathrm{C}$ until analysis. The chemical structures of the stilbenes isolated were confirmed by NMR and MS. ${ }^{8}$ The mobile phase $\left(\mathrm{H}_{2} \mathrm{O}\right.$ and $\left.\mathrm{MeOH}\right)$ gradient program was further modified for the isolation of stilbenes for the structural characterization of the compounds formed after UV irradiation and this fractionation was performed by Shimadzu Prominence HPLC instrument; the modified mobile phase gradient program was 72:28 (t) $0 \mathrm{~min}, 60: 40$ (t) $9 \mathrm{~min}, 50: 50(\mathrm{t}) 13.5 \mathrm{~min}, 30: 70$ (t) $15 \mathrm{~min}, 10: 90$ (t) $17.5 \mathrm{~min}$ and 72:28 (t) 18-21.5 $\mathrm{min}$ with a flow rate of $14 \mathrm{~mL} / \mathrm{min}$.

\subsection{HPLC-DAD/ESI-MS and HPLC-DAD/ESI-MS/MS Analyses}

For the online HPLC-DAD/ESI-MS and HPLC-DAD/ESI-MS/MS analyses, an Agilent 1100 Series liquid chromatography system chromatograph coupled to a Bruker Esquire 3000plus ion trap mass spectrometer (Bruker Daltonics, Bremen, Germany) was utilised. The negative ion HPLC-DAD/ESI-MS experiments were conducted using conditions as follows: scan range $m / z=100-1000$; dry temperature, $300^{\circ} \mathrm{C}$; drying gas, $8.0 \mathrm{~L} / \mathrm{min}$; nebulizer, 20 psi; capillary potential, $4 \mathrm{kV}$; spectra averages, 7 ; rolling averages 1 . The HPLC conditions were the same as the one used for HPLC-DAD analyses. HPLC-DAD/ESIMS/MS of stilbenes was studied by applying a $5 \mathrm{~V}$ supplementary radiofrequency (RF) voltage to the end-caps of the ion trap in order to induce collision with the helium buffer gas present in the ion trap.

\subsection{Stability Assessment of Stilbenes in a Solution and Solid Form}

Stock solutions of reference trans-resveratrol $(290 \mu \mathrm{g} / \mathrm{mL})$, trans-piceatannol $(380 \mu \mathrm{g} / \mathrm{mL})$ and trans-piceid $(270 \mu \mathrm{g} / \mathrm{mL})$ were prepared in $\mathrm{MeOH}$. In addition, stock solutions of isolated stilbenes from our study were prepared in $\mathrm{MeOH}$. The stock solutions of isolated stilbenes were trans-astringin $(120 \mu \mathrm{g} / \mathrm{mL})$, trans-piceid $(40 \mu \mathrm{g} / \mathrm{mL})$, transisorhapontin $(320 \mu \mathrm{g} / \mathrm{mL})$, trans-piceatannol $(90 \mu \mathrm{g} / \mathrm{mL})$, trans-resveratrol $(14 \mu \mathrm{g} / \mathrm{mL})$ and trans-isorhapontigenin $(190 \mu \mathrm{g} / \mathrm{mL})$.

A $5 \mathrm{~mL}$ crude bark extract prior to concentration on a column packed with XAD7HP ETAX was directly taken for stability study. The stability of the isolated stilbenes, reference stilbenes and crude extract was tested under various conditions described in Table 4. Aliquots of each sample were taken after $0 \mathrm{~h}$ (control sample), $24 \mathrm{~h}, 1$ week and 2 weeks for HPLC-DAD, HPLC-DAD/ESI-MS and HPLC-DAD/ESI-MS/MS.

The stability of the solid crude extract was tested under three different conditions (the amounts of dried extracts were in the range of 10-11 mg) described in Table 4. The samples were taken at intervals of $0 \mathrm{~h}$ (control sample), 1 week and 2 weeks for HPLC-DAD analysis. 
Table 4. Stability assessment of stilbenes.

\begin{tabular}{cc}
\hline Stability Conditions in Solution Form & Stability CondItions in Solid Form \\
\hline $\begin{array}{c}\text { (1) Light protected: The samples were stored in } \\
\text { a freezer }\left(-20^{\circ} \mathrm{C}\right) \text { with protection from light in } \\
\text { glass vials capped under ambient air } \\
\text { conditions }\end{array}$ & $\begin{array}{c}\text { (1) Light protected: The solid extract samples } \\
\text { in capped glass vials were stored in a freezer } \\
\left(-20^{\circ} \mathrm{C}\right) \text { protected from light. }\end{array}$ \\
\hline $\begin{array}{c}\text { (2) Light unprotected: The samples in glass } \\
\text { vials (capped under ambient air) were kept on } \\
\text { laboratory bench, exposed to continuous } \\
\text { fluorescent light. }\end{array}$ & $\begin{array}{c}\text { (2) Light unprotected: The solid extract } \\
\text { samples in capped glass vials under ambient } \\
\text { air conditions were kept on laboratory bench, } \\
\text { exposed to continuous fluorescent light. }\end{array}$ \\
\hline & $\begin{array}{c}\text { (3) Light unprotected: Solid extracts samples in } \\
\text { uncapped glass vials were kept on laboratory } \\
\text { bench, exposed to continuous fluorescent light } \\
\text { and permanent contact with air. }\end{array}$ \\
\hline
\end{tabular}

\subsection{UV Stability of Isolated Stilbenes and Crude Extracts}

The UV stability of the isolated stilbenes (in methanol solution), hydrolysed (containing stilbene aglucones) and non-hydrolysed (containing stilbene glucosides) crude extracts under UV radiation were tested by UV lamp with $366 \mathrm{~nm}$ wavelength (UV-A radiation). The stilbenes were placed in vials on the work surface of the UV lamp system and samples were taken at intervals of $0 \mathrm{~h}$ (control sample), $10 \mathrm{~min}, 30 \mathrm{~min}, 1 \mathrm{~h}, 2 \mathrm{~h}, 5 \mathrm{~h}$ and $24 \mathrm{~h}$ for HPLC-DAD analysis. A GC-MS method [1] was also applied to analyse samples at $0 \mathrm{~h}, 2 \mathrm{~h}$ and $24 \mathrm{~h}$.

Larger amounts of bark-derived stilbenes were isolated by semiprep-HPLC for the structural elucidation of new compounds formed during UV irradiation. The stilbenes isolated were irradiated by UV for 6 days and the compounds formed were isolated by prep-HPLC, dried by vacuum centrifuging and identified by MS and NMR.

\subsection{Mass Spectrometry (MS) and Nuclear Magnetic Resonance Spectroscopy (NMR)}

The mass spectrometry analyses were conducted for stilbene glucosides by high resolution ESI-TOF-MS with negative ion mode and for stilbene aglucones by EI-MS (high resolution sector instrument). Acetonitrile-water was used as the solvent. The NMR analyses were performed by $500 \mathrm{MHz}$ and $300 \mathrm{MHz}$ spectrometers. The ${ }^{1} \mathrm{H}$ and ${ }^{13} \mathrm{C}$ spectra were recorded in $\mathrm{CD}_{3} \mathrm{OD}(300 \mathrm{MHz}, 500 \mathrm{MHz}) .{ }^{1} \mathrm{H}$ and ${ }^{13} \mathrm{C}$ chemical shifts were referenced to solvent signals of $\mathrm{CD}_{3} \mathrm{OD}, \delta\left({ }^{1} \mathrm{H}\right)=3.31 \mathrm{ppm}$ and $\delta\left({ }^{13} \mathrm{C}\right)=49.86 \mathrm{ppm}$. The following methods were used to analyse the products formed in UV irradiation studies presented in the chapter concerning the experiments of the UV stability.

For the high-resolution mass spectra (HR-ESI-MS) a JMS-SX102mass spectrometer (JEOL, Tokyo, Japan) was used.

ESI-TOF MS analysis, a Bruker Daltonics micro-TOF-Q I (Bruker Daltonics), the data was processed by means of DataAnalysis 3.2 (Bruker Daltonics). The positive ion ESI-TOF MS analysis was conducted using source conditions as follows: scan range of 0-3000 m/z; dry temperature, $180^{\circ} \mathrm{C}$ : Nitrogen was used as the drying gas, $4.0 \mathrm{~L} / \mathrm{min}$; nebuliser, 04 . bar. Voltages used were: nebulizer end plate $500 \mathrm{~V}$, capillary exit $100 \mathrm{~V}$ and capillary potential $4.5 \mathrm{kV}$.

NMR analysis: $300 \mathrm{MHz}$ Mercury NMR spectrometer (Varian, Palo Alto, CA, USA) and Avance III 500 NMR spectrometer (Bruker Corporation, Billerica, MA, USA) controlled with TopSpin 3.1 (Bruker, Karlsruhe, Germany). All NMR spectra were acquired at $300 \mathrm{~K}$ (for the NMR data see the Supplementary Materials).

\section{Conclusions}

trans-Stilbenes derived from the bark of Norway spruce are stable compounds when stored carefully and protected from light. A trans- to cis-isomerization takes place rapidly upon UV irradiation, but also under fluorescent light after a longer time. 
In this study, we identified new compounds derived from stilbenes from the bark of Norway spruce roots. The individual stilbene molecules were isolated from the extracts and their photochemical stabilities (under fluorescent and UV light) were studied. Isomerisation was much faster in the presence of UV light. The molecular structures of stilbenes change by intramolecular cyclisation (new C-C bond and loss of two hydrogens) to phenanthrene structures. This is the first time that these new phenanthrene structures are reported to be derived from stilbenes of spruce bark.

Supplementary Materials: The following are available on-line. Figure S1: F3.2 fraction: The phenantrene structure formed in the photoisomerization of trans-isorhapotin. ${ }^{1} \mathrm{H}$ - and ${ }^{13} \mathrm{C}-\mathrm{NMR}$ data of F1.2; F1.3; F3.2; F3.4 and F3.5.

Author Contributions: Conceptualization, H.L.-M., T.S., P.S., K.W.; methodology H.L.-M., D.M., R.W., T.S., P.S., K.W., analysis H.L.-M., D.M., R.W., supervision K.W., P.S., writing一original draft preparation, H.L.-M. writing-review and editing, H.L.-M., R.W., D.M., T.S., P.S., K.W. All authors have read and agreed to the published version of the manuscript.

Acknowledgments: Cooperation between LUKE and University of Helsinki is acknowledged. D.M. is grateful for funding from Erasmus Mundus ASC-master program.

Conflicts of Interest: The authors declare no conflict of interest.

\section{References}

1. Latva-Mäenpää, H.; Laakso, T.; Sarjala, T.; Wähälä, K.; Saranpää, P. Variation of stilbene glucosides in bark extracts obtained from roots and stumps of Norway spruce (Picea abies [L.] Karst.). Trees 2013, 27, 131-139. [CrossRef]

2. Hammerbacher, A.; Ralph, S.; Boehlmann, J.; Fenning, T.; Gershenzon, J.; Schmidt, A. Biosynthesis of the major tetrahydroxystilbenes in spruce, astringin and isorhapontin, proceeds via resveratrol and is enhanced by fungal infection. Plant. Physiol. 2011, 157, 876-890. [CrossRef]

3. Franceschi, V.R.; Krokene, P.; Christiansen, E.; Krekling, T. Anatomical and chemical defences of conifer bark against bark beetles and other pests. New Phytol. 2005, 167, 353-375. [CrossRef] [PubMed]

4. Krokene, P. Conifer defense and resistance to bark beetles. In Biology and Ecology of Native and Invasive Species; Vega, F.E., Hofstetter, R.W., Eds.; Elsevier Academic Press: San Diego, CA, USA, 2015; pp. 177-207.

5. Gabaston, J.; Richard, T.; Biais, B.; Waffo-Teguo, P.; Pedrot, E.; Jourdes, M.; Corio-Costet, M.-F.; Mérillon, J.-M. Stilbenes from common spruce (Picea abies) bark as natural antifungal agent against downy mildew (Plasmopara viticola). Ind. Crops Prod. 2017, 103, 267-273. [CrossRef]

6. Freyssin, A.; Page, G.; Fauconneau, B.; Bilan, A.R. Natural stilbenes effects in animal models of Alzheimer's disease. Neural Regen. Res. 2020, 15, 843-849. [CrossRef]

7. Latva-Mäenpää, H.; Laakso, T.; Sarjala, T.; Wähälä, K.; Saranpää, P. Root neck of Norway spruce as a source of bioactive lignans and stilbenes. Holzforschung 2014, 68, 1-7. [CrossRef]

8. Mulat, D.; Latva-Mäenpää, H.; Koskela, H.; Saranpää, P.; Wähälä, K. Rapid chemical characterisation of stilbenes in the root bark of Norway spruce by off-line HPLC/DAD-NMR. Phytochem. Anal. 2014, 25, 529-536. [CrossRef]

9. Likhtenstein, G. Stilbenes-Applications in Chemistry, Life Sciences and Materials Science; Wiley-VCH: Weinheim, Germany, 2010.

10. Välimaa, A.-L.; Raitanen, J.-E.; Tienaho, J.; Sarjala, T.; Nakayama, E.; Korpinen, R.; Mäkinen, S.; Eklund, P.; Willför, S.; Jyske, T. Enhancement of Norway spruce bark side-streams: Modification of bioactive and protective properties of stilbenoid-rich extracts by UVA-irradition. Ind. Crops Prod. 2020, 145, 112150. [CrossRef]

11. Piñeiro, Z.; Palma, M.; Barroso, C.G. Determination of trans-resveratrol in grapes by pressurised liquid extraction and fast high-performance liquid chromatography. J. Chromatogr. A 2006, 1110, 61-65. [CrossRef] [PubMed]

12. Prokop, J.; Abrman, P.; Seligson, A.L.; Sovak, M. Resveratrol and Its Glycon Piceid Are Stable Polyphenols. J. Med. Food 2006, 9 , 11-14. [CrossRef]

13. Shi, G.; Rao, L.; Yu, H.; Xiang, H.; Yang, H.; Ji, R. Stabilization and encapsulation of photosensitive resveratrol within yeast cell. Int. J. Pharm. 2008, 349, 83-93. [CrossRef] [PubMed]

14. Kolouchová-Hanzlíková, I.; Melzoch, K.; Filip, V.; Smidrkal, J. Rapid method for resveratrol determination by HPLC with electrochemical and UV detections in wines. Food Chem. 2004, 87, 151-158. [CrossRef]

15. Trela, B.C.; Waterhouse, A.L. Resveratrol: Isomeric molar absorptivities and stability. J. Agric. Food Chem. 1996, 44, 1253-1257. [CrossRef]

16. Montsko, G.; Pour Nikfardjam, M.S.; Szabo, Z.; Boddi, K.; Lorand, T.; Ohmacht, R.; Mark, L. Determination of products derived from trans-resveratrol UV photoisomerisation by means of HPLC-APCI-MS. J. Photochem. Photobiol. A 2008, 196, 44-50. [CrossRef]

17. Tř́ska, J.; Vrchotová, N.; Olejníčková, J.; Jílek, R.; Sotolář, R. Separation and identification of highly fluorescent compounds derived from trans-resveratrol in the leaves of Vitis vinifera infected by Plasmopara viticola. Molecules 2012, 17, $2773-2783$. [CrossRef] 
18. Yang, I.; Kim, E.; Kang, J.; Han, H.; Sul, S.; Park, S.; Kim, S. Photochemical generation of a new, highly fluorescent compound from nonfluorescent resveratrol. Chem. Commun. 2012, 48, 3839-3841. [CrossRef] [PubMed]

19. Rodríguez, R.A.; Lahoz, I.R.; Faza, O.N.; Cid, M.M.; Lopez, C.S. Theoretical and experimental exploration of the photochemistry of resveratrol: Beyond the simple double bond isomerization. Org. Biomol. Chem. 2012, 10, 9175-9182. [CrossRef] [PubMed]

20. Francioso, A.; Laštovičková, L.; Mosca, L.; Boffi, A.; Bonamore, A.; Macone, A. Gas chromatographic-mass spectrometric method for the simultaneous determination of resveratrol isomers and 2,4,6-trihydroxyphenantrene in red wines exposed to UV-light. J. Agric. Food Chem. 2019, 67, 11752-11757. [CrossRef]

21. Latva-Mäenpää, H. Bioactive and Protective Polyphenolics from roots and stumps of Conifer trees (Norway spruce and Scots pine). Academic Dissertation, University of Helsinki, Helsinki, Finland, 2017.

22. $\mathrm{Hu}, \mathrm{Y} . ; \mathrm{Ma}, \mathrm{S} . ; \mathrm{Li}, \mathrm{J} . ; \mathrm{Yu}, \mathrm{S}$.; Qu, J.; Liu, J.; Du, D. Targeted isolation and structure elucidation of stilbene glycosides from the bark of Lysidice brevicalyx Wei guided by biological and chemical screening. J. Nat. Prod. 2008, 71, 1800-1805. [CrossRef]

23. Jensen, J.S.; Wertz, C.F.; O’Neill, V.A. Preformulation stability of trans-resveratrol and trans-resveratrol glucoside (piceid). J. Agric. Food Chem. 2010, 58, 1685-1690. [CrossRef]

24. Leong, Y.-W.; Harrison, L.; Powell, A. Phenanthrene and other aromatic constituents of Bulbophyllum vaginatum. Phytochemistry 1999, 50, 1237-1241. [CrossRef]

25. Moore, W.; Morgan, D.; Stermitz, F. The photochemical conversion of stilbene to phenanthrene. The nature of the intermediate. J. Am. Chem.Soc. 1963, 86, 829-830. [CrossRef]

26. Sigman, M.; Barbas, J.; Corbett, S.; Chen, Y.; Ivanov, I.; Dabestani, R. Photochemical reactions of trans-stilbene and 1,1diphenylethylene on silica gel: Mechanisms of oxidation and dimerization. J. Photochem. Photobiol. A: Chemistry 2001, 138, 269-274. [CrossRef] 